\title{
Non-infectious Complications of Peritoneal Dialysis among Sudanese Patients: Five Years Experience
}

Maysoon O Mekki $i^{* 1,2}$, Haleema M Fedail ${ }^{1,2}$, Eltigani MA Ali ${ }^{1,3}$, Mohammed B Abdelraheem ${ }^{1,3}$, Hanan Al-Sanousi ${ }^{1,2}$, Sarra Elamin ${ }^{1,3}$, Babikir J Kaballo ${ }^{1,4}$, Layla Tammam ${ }^{1,5}$, Hisham H Abdelwahab ${ }^{1,2}$, Safaa A Medani ${ }^{1,6}$, Ammar H Khamis ${ }^{7}$, Hasan Abu-Aisha ${ }^{1}$

(1) Sudan Peritoneal Dialysis Program and Nephrology Departments of (2) Khartoum Teaching Hospital, (3) Soba Teaching Hospital, (4) Military Hospital, (5) Ibn Sina Hospital and (6) Jaafar Ibn Auf Hospital, and (7) Biostatistics Department of Sudan University for Science and Technology; Khartoum, Sudan

\begin{abstract}
Introduction: The technique of Continuous Ambulatory Peritoneal Dialysis (CAPD) is known to be associated with various infectious and non-infectious complications. The latter term includes anatomical/mechanical complications as well as hemoperitoneum, inflow pain, electrolyte disturbances, metabolic derangements and delayed gastric emptying.

Methods: We retrospectively evaluated all patients who were maintained on CAPD for a minimum of 90 days in Sudan, in the period between May 2005 and Apr 2010. We examined the incidence of various non-infectious complications and their possible associations.

Results: The analysis included 296 patients including 71 children (24\%). Males constituted $62.2 \%$ of the study population and $13.9 \%$ were diabetic. The incidence per 100 patient-years of various non-infectious complications was as follows: hypokalemia (30.4), catheter dysfunction (10.8), dialysate leak (5.3), hernia (4.7), hemorrhagic effluent (4.7), inflow pain (2.3), upper gastrointestinal symptoms (2) and cuff extrusion (0.9). Catheter block and hernia were diagnosed with a median duration after catheter insertion of 6 and 7.5 months, respectively. Catheter block was significantly more prevalent among children $(22.5 \%$ versus $9.3 \%$; $\mathrm{P}=0.006)$. A high body mass index (BMI) was the only identified independent predictor for leak (OR 1.4, $\mathrm{P}=0.005$ ). More than half of the 16 hernias were umbilical, and four of the five inguinal hernias were bilateral. Non-infectious complications were responsible for $32 \%$ of technique failures.
\end{abstract}

Conclusion: Non-infectious complications were fairly common among our CAPD patients and led to catheter removal in a considerable number of patients.

\footnotetext{
* Corresponding author; Nephrology Department, Khartoum Teaching Hospital, Khartoum, Sudan
}

Keywords: Hernia; Leak; Non-infectious Complications; Peritoneal Dialysis; Sudan

\section{The authors declared no conflict of interest}

\section{Introduction}

Continuous Ambulatory Peritoneal Dialysis (CAPD) was first introduced in the Sudan in May 2005. It is operated as a national program, with seven centers in the capital Khartoum and one center in Gezira State. The technique of CAPD is known to be associated with various infectious and non-infectious complications. Infectious complications include peritonitis and exit site infections. The term non-infectious complications is generally understood tomeananatomical/mechanicalcomplications, such as hernias, leaks and catheter dysfunction among others [1-4]. However, non-infectious complications related to CAPD also include hemoperitoneum, inflow pain, hypokalemia and delayed gastric emptying [5-7]. Overall, anatomical complications were reported in $10-19 \%$ of CAPD patients [8-10].

This study was designed to measure the incidence of non-infectious complications among Sudanese CAPD patients, to identify the various associated risk factors, and to measure the impact of these complications on dialysis.

\section{Methods}

This is a retrospective study, conducted in all functioning CAPD centers in the Sudan. It included all patients who underwent soft peritoneal catheter insertion in the period between the 1st of May 2005 and the 30th of Apr 2010 and were maintained on peritoneal dialysis for a minimum duration of 90 days. After obtaining informed consent, information was collected from the patients' records and through direct or phone interviews with patients and/or their care-givers. This included clinical and demographic 
Table 1: The incidence of non-infectious complications among Sudanese patients maintained on CAPD for $\geq 90$ days between May 2005 and April 2010

\begin{tabular}{lll}
\hline Event & Number & $\begin{array}{l}\text { Incidence per } \\
\text { 100 patient- } \\
\text { years }\end{array}$ \\
\hline Hypokalemia & 104 & 30.4 \\
Catheter dysfunction & 37 & 10.8 \\
Dialysate leak & 18 & 5.3 \\
Hernia & 16 & 4.7 \\
Hemorrhagic effluent & 16 & 4.7 \\
Inflow pain & 8 & 2.3 \\
Upper gastrointestinal symptoms & 7 & 2.0 \\
Cuff extrusion & 3 & 0.9 \\
\hline
\end{tabular}

data, dates of catheter insertion and removal, and causes for catheter removal.

Analysis was done using SPSS for windows version 17 (SPSS Inc. Chicago, IL, USA). Data were summarized in the form of means and proportions as appropriate. Chi square test was used to examine for significant associations.

\section{Results}

The analysis included 296 patients, including 71 children aged 18 years or less (24\%). Males constituted $62.2 \%$ of the study population and $13.9 \%$ were diabetic. The total CAPD duration was 4101 patient-months. Overall, 41 patients $(12 \%)$ required more than one $\mathrm{PD}$ catheter, including six patients who required three PD catheters. Most PD catheters were placed by mini-laparotomy or modified mini-laparotomy, and some were placed using the percutaneous technique. Laparoscopy was not used for catheter placement in any patient. The incidence rate of various non-infectious complications is shown (Table 1).

The commonest anatomical/mechanical event was catheter block, with an incidence of 10.8 per 100 patientyears. The median time for diagnosis was six months post catheter insertion. Significantly more children suffered from catheter block than adults $(22.5 \%$ versus $9.3 \%$; $\mathrm{P}$ $=0.006)$. Partial omentectomy was needed in 9 out 16 children with catheter block. The prevalence of catheter block among patients with history of prior intermittent peritoneal dialysis using a hard catheter tended to higher than patients without such history, but the difference was not statistically significant $(19.4 \%$ versus $10.1 \%$; $\mathrm{P}=$ $0.11)$.
Most episodes of leak occurred early after catheter insertion, and only two episodes occurred late (1 exit site and 1 trans-vaginal leak). In logistic regression analysis, the only independent predictor for the occurrence of leak was body mass index (Table 2).

Hernias were noted to occur after a median duration of 7.5 months. The prevalence of hernia among children was $1.4 \%$ compared to $7.6 \%$ among adults, but the different was not statistically significant $(\mathrm{P}=0.1)$. Hernias were umbilical in more than half the cases $(57.9 \%)$. The remainder were inguinal $(26.3 \%)$ and incisional $(15.8 \%)$. Four out of five inguinal hernias were bilateral. Two hernias were complicated by intestinal obstruction requiring urgent surgical intervention.

Overall, non-infectious complications were responsible for $32 \%$ of technique failures.

\section{Discussion}

The incidence of non-infectious complications in this cohort of CAPD patients was similar to figures reported from elsewhere (10-19\%) [8-11]. In this study, noninfectious complications contributed to more than one third of technique failures. This is comparable to what has been reported by Weber J et al, that $49 \%$ of catheter failures were due to mechanical complications [12].

In our cohort of patients, the prevalence of leak was higher than some reports $(2.25-3 \%)$ [1, 8,13-15] and lower than others $(15-25 \%)[10,15,16]$. This may be due to difference in population characteristics. We found significant association of leak with higher BMI, and other researchers reported similar findings $[16,17]$.

The prevalence of hernia in our patients was less than that reported by several other investigators, both regionally and internationally[15, 16, 18, 19]. However, it was comparable to some reports from the USA and Spain [8, 20]. Some researchers reported an association of hernia with male gender and cystic disease [8, 16], but we did not find such an association. The prevalence of catheter obstruction was higher in our adult CAPD patients than what has been reported by some investigators $[1,10,13$, $14,21]$, though it was less than that reported by Huraib et al in KSA [15]. Also, hemorrhagic effluents were less than that reported by others $[1,10,22,23]$.

The prevalence of leak, hernia, and cuff extrusion in our CAPD children was less than that reported by other investigators [24-26], although our patients had more incidence of catheter block in comparison to the mentioned reports. Macchini et al [27], reported a leak prevalence comparable to ours . 
Table 2: Risk factors associated the occurrence of dialysate leak among Sudanese patients maintained on CAPD for $\geq$ 90 days between May 2005 and April 2010

\begin{tabular}{lll}
\hline Risk factor & Odds ratio & P value \\
\hline Body mass index (BMI), $\mathrm{kg} / \mathrm{m}^{2}$ & 1.4 & 0.005 \\
Female gender & 15 & 0.1 \\
Diabetes mellitus & 2.7 & 0.6 \\
Age, years & 0.9 & 0.9 \\
Break in period, days & 1.0 & 0.3 \\
\hline
\end{tabular}

Catheter block was significantly more common among our studied children compared to adults. This might be related to the fact that children have a relatively larger omentum, increasing the risk of omental wrap. The incidence of hernia in our children was lower than adults. This was difficult to explain.

Hypokalemia prevalence in our studied patients was comparable to that of other reports (10-35\%) [7, 28-30]. The presence of hypokalemia, hypoalbuminemia, and hypophosphatemia could be indicators of malnutrition.

\section{Conclusion}

Non-infectious complications were fairly common among our CAPD patients, and they had led to catheter removal in a considerable number of patients. Care is therefore needed to screen CAPD patients for these complications in order to timely address and manage these problems.

\section{References}

1. Tiong HY, Poh J, Sunderaraj K, Wu YJ, Consigliere DT. Surgical complications of Tenckhoff catheters used in continuous ambulatory peritoneal dialysis. Singapore Med J. 2006 Aug;47(8):707-11.

2. Vaamonde CA, Michael UF, Metzger RA, Carrol KE JR. complications of acute peritoneal dialysis. J Chronic Dis. 1975 Dec;28(11-12): 637-59.

3. Mactier RA, Sprosen ST, Gokal R, etal. Bicarbonate and bicarbonate/lactate peritoneal dialysis solutions for the treatment of infusion pain. Kidney Int. 1998 Apr;53(4):1061-7.

4. Ozener C, Bihorac A, Akoglu E. Technical Survival of CAPD Catheters: Comparison between percutaneous and conventional surgical techniques. Nephrol Dial Transplant. 2001 Sep;16(9):1893-9.

5. Stompór T, Hubalewska-Hola A, Staszczak A, Sulowicz W, Huszno B, Szybinski Z.Association between gastric emptying rate and nutritional status in patients treated with continuous ambulatory peritoneal dialysis. Perit Dial Int. 2002 Jul-Aug;22(4):500-5.

6. Nakamoto H, Imai H, Kawanishi H, Nakamoto M, Minakuchi J, Kumon S, Watanabe S, Shiohira Y, Ishii T, Kawahara T, Suzuki H. Low serum albumin in elderly continuous ambulatory peritoneal dialysis patients is attributable to high permeability of peritoneum. Adv Perit Dial. 2001;17:238-43

7. Khan AN, Bernardini J, Johnston JR, Piraino B. Hypokalemia in peritoneal dialysis patients. Perit Dial Int. 1996 Nov-Dec;16(6): 652.

8. Van Dijk CM, Ledesma SG, Teitelbaum I. Patient characteristics associated with defects of the peritoneal cavity boundary. Perit Dial Int. 2005 Jul-Aug; 25(4):36773.

9. Chen SY, Chen TW, Lin SH, Chen CJ, Yu JC, Lin CH. Does previous abdominal surgery increase postoperative complication rates in continuous ambulatory peritoneal dialysis. Perit Dial Int. 2007 Sep-Oct;27(5):557-9.

10. Schmidt SC, Pohle C, Langrehr JM, Schumacher G, Jacob D, Neuhaus P. Laparoscopic-assisted placement of peritoneal dialysis catheters: implantation technique and results. J Laparoendosc Adv Surg Tech A. 2007 Oct; 17(5):596-9.

11. Tăranu T, Covic A, Suditu N. The surgical problems of continuous ambulatory peritoneal dialysis: 3 years of experience. Rev Med Chir Soc Med Nat Iasi. 1998 JulDec;102(3-4):167-70.

12. Weber J, Mettang T, Hübel E, Kiefer T, Kuhlmann U. Survival of 138 surgically placed straight double-cuff Tenckhoff catheters in patients on continuous ambulatory peritoneal dialysis. Perit Dial Int. 1993;13(3):224-7.

13. Apostolidis NS, Panoussopoulos DG, Manouras AJ, Pararas BN, Voudiklari SG, Zirogiannis PN. The use of TWH catheters in CAPD patients: fourteen-year experience in technique, survival, and complication rates. Perit Dial Int. 1998 Jul-Aug; 18(4):424-8.

14. Allon M, Soucie JM, Macon EJ. Complications with permanent peritoneal dialysis catheters: experience with 154 percutaneously placed catheters. Nephron. 1988;48(1):8-11.

15. Huraib S, Abu-Aisha HA, Memon NA, Al-Wakeel J, Mitwali A, Al-Khudairy N. Non-peritonitis complications of continuous ambulatory peritoneal dialysis in Saudi Arabia. Ann Saudi Med. 1995 Sep;15(5):458-61.

16. Del Peso G, Bajo MA, Costero O, Hevia C, Gil F, Díaz C, Aguilera A, Selgas R. Risk factors for abdominal wall complications in peritoneal dialysis patients. Perit Dial Int. 2003 May-Jun;23(3):249-54 
17. Song JH, Kim GA, Lee SW, Kim MJ.Clinical outcomes of immediate full-volume exchange one year after peritoneal catheter implantation for CAPD. Perit Dial Int. 2000 Mar-Apr;20(2):194-9.

18. Tokgöz B, Dogukan A, Güven M, Unlühizarci K, Oymak O, Utas C. Relationship between different body size indicators and hernia development in CAPD patients. Clin Nephrol. 2003 Sep; 60(3):183-6.

19. Sanderson MC, Swartzendruber DJ, Fenoglio ME, Moore JT, Haun WE. Surgical complications of continuous ambulatory peritoneal dialysis. Am J Surg. 1990 Dec;160(6):561-5.

20. García-Ureña MA, Rodríguez CR, Vega Ruiz V, Carnero Hernández FJ, Fernández-Ruiz E, Vazquez Gallego JM, Velasco García M. Prevalence and management of hernias in peritoneal dialysis patients. Perit Dial Int. 2006 Mar-Apr; 26(2):198-202.

21. Yang PJ, Lee CY, Yeh CC, Nien HC, Tsai TJ, Tsai MK. Mini-laparotomy implantation of peritoneal dialysis catheters: outcome and rescue. Perit Dial Int. 2010 Sep;30(5):513-8.

22. Tse KC, Yib PS, Lam MF, Li FK, Choy BY, Chan TM, Lai KN. Recurrent hemoperitoneum complicating continuous ambulatory peritoneal dialysis. Perit Dial Int. 2002 Jul-Aug;22(4):488-91.

23. Greenberg A, Bernardini J, Piraino BM, Johnston JR, Perlmutter JA. Hemoperitoneum complicating chronic peritoneal dialysis: single-center experience and literature review. Am J Kidney Dis. 1992 Mar;19(3):252-6.

24. Tsai TC, Huang FY, Hsu JC, Lee ML, Chou LH. Continuous ambulatory peritoneal dialysis complicating with abdominal hernias in children. Zhonghua Min Guo Xiao Er Ke Yi Xue Hui Za Zhi. 1996 JulAug;37(4):263-5.

25. Stone MM, Fonkalsrud EW, Salusky IB, Takiff H, Hall T, Fine RN. Surgical management of peritoneal dialysis catheters in children: five-year experience with 1,800 patient-month follow-up. J Pediatr Surg. 1986 Dec;21(12):1177-81.

26. Rinaldi S, Sera F, Verrina E, Edefonti A, Gianoglio B, Perfumo F, Sorino P, Zacchello G, Cutaia I, Lavoratti G, Leozappa G, Pecoraro C, Rizzoni G; Italian Registry of Pediatric Chronic Peritoneal Dialysis. Chronic peritoneal dialysis catheters in children: a fifteen-year experience of the Italian Registry of Pediatric Chronic Peritoneal Dialysis. Perit Dial Int. 2004 Sep-Oct;24(5):481-6.

27. Macchini F, Valadè A, Ardissino G, Testa S, Edefonti A, Torricelli M, Luzzani S. Chronic peritoneal dialysis in children: catheter related complications. A single centre experience. Pediatr Surg Int. 2006 Jun;22(6):524-8.

28. Oreopoulos DG, Khanna R, Williams P, Vas SI. Continuous ambulatory peritoneal dialysis- 1981. Nephron 1982;30:293.

29. Spital A, Sterns RH. Potassium supplements via the dialyzate in continuous ambulatory peritoneal dialysis. Am J Kidney Dis. 1985 Sep;6(3):173-6.

30. Szeto CC, Chow KM, Kwan BC, Leung CB, Chung KY, Law MC, Li PK. Hypokalemia in Chinese peritoneal dialysis patients: prevalence and prognostic implication. Am J Kidney Dis. 2005 Jul;46(1):128-35. 